\title{
PHYSICAL CONTACT BETWEEN HUMAN VASCULAR ENDOTHELIAL AND SMOOTH MUSCLE CELLS MODULATES CYTOSOLIC AND NUCLEAR CALCIUM HOMEOSTASIS
}

\begin{tabular}{|c|c|}
\hline Journal: & Canadian Journal of Physiology and Pharmacology \\
\hline Manuscript ID & cjpp-2018-0093.R1 \\
\hline Manuscript Type: & Article \\
\hline Date Submitted by the Author: & 23-Mar-2018 \\
\hline Complete List of Authors: & $\begin{array}{l}\text { Hassan, Ghada; Départment d'anatomie et biologie cellulaire } \\
\text { Jacques, Danielle; Anatomy and Cell Biology, Anatomy and Cell Biology } \\
\text { D'Orleans-Juste, Pedro; Universite de Sherbrooke, Pharmacology and } \\
\text { Physiology } \\
\text { Magder, Sheldon; Mcgill University Health Centre } \\
\text { Bkaily, Ghassan; Départment d'anatomie et biologie cellulaire, }\end{array}$ \\
\hline $\begin{array}{l}\text { Is the invited manuscript for } \\
\text { consideration in a Special } \\
\text { Issue: }\end{array}$ & IACS Orlando \\
\hline Keyword: & $\begin{array}{l}\text { vascular endothelial cells, vascular smooth muscle cells, co-culture, nuclear } \\
\text { calcium, calcium release }\end{array}$ \\
\hline
\end{tabular}




\section{PHYSICAL CONTACT BETWEEN HUMAN VASCULAR ENDOTHELIAL AND SMOOTH MUSCLE CELLS MODULATES CYTOSOLIC AND NUCLEAR CALCIUM HOMEOSTASIS}

Ghada S. Hassan ${ }^{1}$, Danielle Jacques ${ }^{1}$, Pedro D’Orleans-Juste ${ }^{2}$, Sheldon Magder ${ }^{3}$ and Ghassan Bkaily ${ }^{1 *}$

${ }^{1}$ Department of Anatomy and Cell Biology

${ }^{2}$ Department of Pharmacology and Physiology

Faculty of Medicine, Université de Sherbrooke

Sherbrooke, Quebec, Canada J1H 5N4

${ }^{3}$ Mcgill University Health Centre, Montreal, Quebec, Canada H3A 1A1

\section{Short title: Physical contact between human vascular endothelial and smooth}

muscle cells

*Corresponding author:

Dr. Ghassan Bkaily

Department of Anatomy and Cell Biology

Faculty of Medicine - Université de Sherbrooke

$300112^{\text {th }}$ Avenue North

Sherbrooke, Quebec, Canada J1H 5N4

Tel.: (819) 564-5303

Email: Ghassan.Bkaily@USherbrooke.ca 


\begin{abstract}
The interaction between vascular endothelial cells (VECs) and vascular smooth muscle cells (VSMCs) plays an important role in the modulation of vascular tone. There is however no information on whether direct physical communication regulates the intracellular calcium levels of human VECs (hVECs) and/or hVSMCs. Thus, the objective of the study is to verify whether co-culture of hVECs and hVSMCs modulates cytosolic $\left(\left[\mathrm{Ca}^{2+}\right]_{\mathrm{c}}\right)$ and nuclear calcium $\left(\left[\mathrm{Ca}^{2+}\right]_{\mathrm{n}}\right)$ levels via physical contact and/or factors released by both cell types. Quantitative $3 \mathrm{D}$ confocal microscopy for $\left[\mathrm{Ca}^{2+}\right]_{\mathrm{c}}$ and $\left[\mathrm{Ca}^{2+}\right]_{\mathrm{n}}$ measurement was performed in cultured hVECs or hVSMCs or in co-culture of hVECshVSMCs. Our results show that: 1) physical contact between hVECs-hVECs or hVSMCs-hVSMCs does not affect $\left[\mathrm{Ca}^{2+}\right]_{\mathrm{c}}$ and $\left[\mathrm{Ca}^{2+}\right]_{\mathrm{n}}$ in these two cell types; 2) physical contact between hVECs and hVSMCs induces a significant increase only of $\left[\mathrm{Ca}^{2+}\right]_{\mathrm{n}}$ of hVECs without affecting the level of $\left[\mathrm{Ca}^{2+}\right]_{\mathrm{c}}$ and $\left[\mathrm{Ca}^{2+}\right]_{\mathrm{n}}$ of $\mathrm{hVSMCs}$; and 3) preconditioned culture medium of hVECs or hVSMCs does not affect $\left[\mathrm{Ca}^{2+}\right]_{\mathrm{c}}$ and $\left[\mathrm{Ca}^{2+}\right]_{\mathrm{n}}$ of both types of cells. We concluded that physical contact between hVECs and hVSMCs only modulates $\left[\mathrm{Ca}^{2+}\right]_{\mathrm{n}}$ in hVECs. The increase of $\left[\mathrm{Ca}^{2+}\right]_{\mathrm{n}}$ in hVECs may modulate nuclear functions that are calcium dependent.
\end{abstract}

Keywords: vascular endothelial cells, vascular smooth muscle cells, co-culture, nuclear calcium, calcium release. 


\section{Introduction}

Physical contact between the same type of cells involves different types of junctions such as tight junctions (Alberts et al., 1994), adherence junctions (Alberts et al., 1994), PECAM (PlateletEndothelial cell adhesion molecule) (Delisser et al., 1994), integrins (Alberts et al., 1994 ; Hynes, 1987) and gap junctions (Bény and Pacicca, 1994; Hirschi et al., 1999; Goodenough, 1979 ; Alberts et al., 1994). The latter, the most common type of junctions present in all cell types as well as between two different cell types (Alberts et al.,1994), permits both electrical and small molecule-mediated chemical coupling between cells. This type of junctions is very well studied and early reports have shown its presence both in vivo and in vitro between vascular endothelial (VECs) and smooth muscle (VSMCs) cells (Spagnoli et al., 1982; Christ et al, 1996). These junctions usually consist of connexin $40(\mathrm{Cx} 40)$ and $43(\mathrm{Cx} 43)$ in addition to $\mathrm{Cx} 37$ (Elfgang et al., 1995; Kurtz, 2015; Donahue et al., 2017; Meda, 2018). Changes in gap junctions are known to alter intercellular coupling between VECs and VSMCs thus modulating intercellular chemical coupling in diseases (Donahue et al., 2017 and references within) such as hypertension neointimal hyperplasia, and endothelial denudation (Cuevas et al., 1982; Cuevas and Diaz, 1982; Grunwald et al., 1982; Huttner et al., 1985; Kurtz, 2015; Okamoto and Suzuki, 2017; Meda, 2018). Several studies showed the presence of all types of junctions in VECs and VSMCs. However, very few studies investigate whether junctions between VECs or VSMCs or between VECs and VSMCs would affect intracellular ionic homeostasis in general and in particular intracellular calcium. In addition, nuclear calcium was also reported to be regulated by cytosolic factors such as endothelin-1 (ET-1) (Bkaily et al., 2011, 2012).

We herewith demonstrate that physical contact does not regulate intracellular calcium level in human VECs (hVECs) nor VSMCs (hhVSMCs) in pure cultures. However, physical contact between hVECs and hVSMCs induced an increase in intracellular calcium particularly at the nuclear level only in hVECs. 


\section{Materials and Methods}

\section{Isolation and culture of human aortic endothelial and smooth muscle cells}

All work was done in accordance with the requirements of the institutional review committee for the use of human material. As described previously (Bkaily et al. 1997, 2017; Avedanian et al. 2010), human VECs and VSMCs were isolated from aortas of at least 3 different healthy donors (16-45 years old) supplied by Transplant Québec. Briefly, freshly isolated VECs and VSMCs used in this study were obtained by scraping from collagenase-treated aortas. The cells were then cultured in M199 medium supplemented with 5\% FBS and used between passages 2 and 6 . Routine quality and purity checks of the hVECs and hVSMCs were done using specific probes as indicated elsewhere (Bkaily et al. 1997; Avedanian et al. 2010). The aortic hVECs derivation was also confirmed by assessing the presence of Von Willebrand factor (Bkaily et al. 1997; Avedanian et al. 2010) and that of hVSMCs using $\alpha$-smooth muscle cell actin and/or myosin light chain kinase antibodies. Furthermore, functional quality control of freshly cultured (used within $12 \mathrm{~h}$ of culture) and long-term cultured (passage 2-6) cells was routinely done to ensure that both cultures had similar densities and distribution of ET-1 and angiotensin (Ang) II receptors and responded similarly to ET-1, Ang II, and high extracellular $\mathrm{K}^{+}(30 \mathrm{mmol} / \mathrm{L})$ by increasing $\left[\mathrm{Ca}^{2+}\right]_{\mathrm{i}}$ (Bkaily et al. 1997; Avedanian et al. 2010).

\section{Co-culture of VECs and VSMCs}

Isolated hVECs and hVSMCs were co-cultured as previously reported (Bkaily et al., 1997, 2001). In brief, since hVSMCs adhere more easily than hVECs, the former cells are cultured first. A drop of medium containing a high concentration of hVSMCs is placed in 
the center of a round glass coverslip $(25 \mathrm{~mm})$ present in a small petri culture dish. A period of one hour is necessary to ensure the attachment of the cells to the coverslip. Then, $2 \mathrm{ml}$ of culture medium is added into the petri dish and incubated at $37^{\circ} \mathrm{C}$ for a period of 18-24 hours. Subsequently, the culture medium of hVSMCs was replaced with culture medium containing a high concentration of hVECs and both cell types were incubated for a period of 24-48 hours before being used. This simple technique allows the study of contact development between hVECs and hVSMCs (cell-cell).

\section{Loading with Fluo-3 AM}

The hVECs and hVSMCs in pure culture as well as in co-culture, were loaded with the calcium probe, Fluo-3, as previously described (Baily et al., 1997; Bkaily and Jacques, 2010). Briefly, the cells cultured on $25 \mathrm{~mm}$ coverslips were washed three times with Tyrode buffer (5 mM HEPES, $136 \mathrm{mM} \mathrm{NaCl}, 2.7 \mathrm{mM} \mathrm{KCl,} 1 \mathrm{mM} \mathrm{MgCl}$ 2, $1.9 \mathrm{mM} \mathrm{CaCl}$ 2, $5.6 \mathrm{mM}$ glucose, $\mathrm{pH} 7.4$ adjusted with Tris base, $310 \mathrm{mOsm}$ ) supplemented with $0.1 \%$ BSA (bovine serum albumin) (Sigma, St Louis). The cells were then incubated with the calcium probe, Fluo-3 /AM (Molecular Probes, Eugene, OR) at a final concentration of $13 \mu \mathrm{M}$ (Bkaily et al., 1997) at RT for 1 hour. After the incubation period, the cells were washed 3 times in the Tyrode buffer alone and were then left in the Tyrode buffer for 15 minutes in order to ensure complete hydrolysis of the acetoxymethyl ester groups before starting the experiments. Fluo-3 was found to be homogeneously distributed throughout the cells (Bkaily et al. 2001, 2003) and was calibrated to be expressed in absolute concentration of free $\mathrm{Ca}^{2+}$ (Bkaily et al. 2001).

\section{Quantitative 3D confocal microscopy, volume rendering, and quantitative}

\section{fluorescence intensity measurement}


Cells were examined with a Multiprobe 2001 confocal krypton-argon laser scanning system (Molecular Dynamics, Sunnyvale, California, USA) as previously described (Bkaily et al. 1997, 2010, 2017; Ahmarani et al. 2013). In brief, all confocal microscope settings (laser line intensity, photometric gain, PMT settings, and filter attenuation) were kept rigorously constant throughout all the experiments (Bkaily et al. 1997, 1999, 2010 2017). At the end of each experiment, the nucleus was stained with $100 \mathrm{nmol} / \mathrm{L}$ of live cell nucleic acid stain SYTO-11 (Molecular Probes, Eugene, Oregon, USA), as described previously (Bkaily et al. 1997, 2017). Real 3D projections of the nucleus (Bkaily et al. 1997) were used as templates to delineate the nuclear from the cytosolic compartment. Scanned images were transferred onto a Silicon Graphics workstation equipped with Molecular Dynamics' ImageSpace analysis and Volume Workbench software modules. For quantification of the 3D images, the ImageSpace program permits the generation of quantitative 3D images which in turn allows fluorescence intensity measurement and expression of the measurement per $\mu \mathrm{m}^{3}$. Images were represented as top-view maximum intensity real 3D projections (not deconvolution) (Bkaily et al. 2017).

\section{Conditioned media}

We wanted to verify if, during the period of a $\mathrm{Ca}^{2+}$ measurement experiment, factors are released in the medium and affect the calcium level of one or both cell types. hVECs or hVSMCs were loaded with Fluo-3 and placed in a Tyrode buffer for 30-45 min (short term), the period normally estimated for a typical experiment for measuring basal intracellular $\mathrm{Ca}^{2+}$ in a cell. This Tyrode solution is subsequently collected and used as a bath medium in the coverslip chamber for cells of the same cell type (control) or of the 
other cell type. Then, the fluorescence intensity of the Fluo-3-Ca ${ }^{2+}$ complex of the cells is measured by confocal microscopy.

We also wanted to verify if, during the period when both cell types are cultured together (24-48hr, long term), factors are released in the medium and affect the basal $\mathrm{Ca}^{2+}$ level of one or both cell types. The medium of hVECs or hVSMCs at confluence is removed and a fresh medium is added. The latter medium is collected after 48 hours, filtered and added to the petri dishes with cells of the same type (control), or of the other cell type and left for 24 hours. Subsequently, the cells were loaded with Fluo-3 and the fluorescence intensity of the Fluo-3-Ca ${ }^{2+}$ complex in the cells is measured by confocal microscopy. As for the pure cultures of ECs and VSMCs, the conditioned medium of co-cultures is collected as described above. Subsequently, the medium is added in petri dishes of hVECs or hVSMCs for $24 \mathrm{~h}$ and the fluorescence intensity of the Fluo-3-Ca ${ }^{2+}$ complex of the cells is measured.

\section{Statistics}

The intensity levels of free cytosolic and nuclear calcium are represented either as average values of relative fluorescence intensity, or as an increase over the control level ( 0 calcium $)$. The values are expressed as mean \pm S. E.M. Statistical significance was determined using the ANOVA repeated measures test for partial values followed by the Tukey-Kramer test or the Student-Newman-Keuls test with the multiple comparison to establish the statistical value of the results. P values less than 0.05 were considered significant. 


\section{Results}

\section{Effect of hVEC-hVEC and hVEC-hVSMC contact on $\left[\mathrm{Ca}^{2+}\right]_{c}$ and $\left[\mathrm{Ca}^{2+}\right]_{\mathrm{n}}$ of hVECs.}

In the first series of experiments, we cultured hVECs at low density in order to obtain a high density of single cells without physical contact. In the second series of experiments, we cultured hVECs at a high density in order to obtain a high density of cells that develop physical contacts. In the third series of experiments, we first cultured hVSMCs at low density and after 24 hrs, the cells were well attached and we added a new culture medium containing a high concentration of hVECs in order to obtain a maximum of physical contact between hVSMCs and hVECs. In each series of experiments, we loaded the cells with the calcium probe fluo-3, as described previously, and $\left[\mathrm{Ca}^{2+}\right]_{\mathrm{c}}$ and $\left[\mathrm{Ca}^{2+}\right]_{\mathrm{n}}$ were recorded using quantitative $3 \mathrm{D}$ confocal microscopy. Figure $1 \mathrm{~A}-\mathrm{C}$ shows examples and figure 1D summarizes the results. As can be seen in figure $1 \mathrm{~A}$, the level of calcium is higher in the nucleus compared to the cytosol in hVECs as was reported previously (Bkaily et al., 2011). As seen in figure $1 \mathrm{~A}$ and B, physical contact between hVECs did not affect cytosolic calcium distribution and levels. However, physical contacts between several hVECs with a single hVSMC induced an apparent increase of intracellular calcium, and more markedly at the nuclear level, of hVECs. Figure 1D shows that the increase of intracellular calcium in hVECs in contact with hVSMCs is mainly significant at the nuclear level when compared to the level of cytosolic and nuclear calcium in hVECs and hVECs-hVECs. Noteworthly, contact between hVECs induced a 4\% decrease of $\left[\mathrm{Ca}^{2+}\right]_{\mathrm{c}}$ and $3.3 \%$ increase of $\left[\mathrm{Ca}^{2+}\right]_{\mathrm{n}}$ compared to individually growing cells. These changes are not statistically significant. However, when compared to individually growing hVECs, the level of $\left[\mathrm{Ca}^{2+}\right]_{\mathrm{c}}$ increased by $11 \%$ in hVECs in contact with hVSMCs and this was statistically insignificant. Moreover, $\left[\mathrm{Ca}^{2+}\right]_{\mathrm{n}}$ significantly increased 
$(\mathrm{p}<0.05)$ in hVECs in contact with hVSMCs when compared to individually growing cells.

Effect of hVSMC-hVSMC and hVEC-hVSMC contact on $\left[\mathrm{Ca}^{2+}\right]_{c}$ and $\left[\mathrm{Ca}^{2+}\right]_{\mathrm{n}}$ of hVSMCs.

In another set of experiments, using the same approaches described above, we cultured hVSMCs at low density, high density as well as in co-culture with hVECs. Figure 2 A-C shows examples and figure $2 \mathrm{D}$ summarizes the results. As can be seen in figure $2 \mathrm{~A}$, the apparent nuclear calcium level is higher than that in the cytosol in single hVSMCs. The distribution as well as the level of cytosolic and nuclear calcium did not change in hVSMCs that developed physical contacts (Figure $2 \mathrm{~B}$ ). As seen in figure $2 \mathrm{C}$ however, co-culturing hVSMCs with hVECs did not affect the distribution and the level of cytosolic and nuclear calcium of hVSMCs. In contrast, hVECs in contact with hVSMCs have a higher nuclear calcium level (Figure $2 \mathrm{C}$ ). As seen in figure $2 \mathrm{D}$, neither contact between hVSMCs nor contact between hVSMCs and hVECs significantly affect cytosolic and nuclear calcium distribution and levels in hVSMCs.

\section{Effect of conditioned medium of hVECs, hVSMCs and hVECs-hVSMCs co-culture on cytosolic and nuclear calcium of hVECs.}

In order to verify whether the increase of nuclear calcium in endothelial cells in physical contact with hVSMCs is due to a factor released in the extracellular milieu, we collected the culture medium of each culture condition. We then exposed cultured hVECs loaded with the calcium probe fluo-3 to each collected medium: hVECs, hVSMCs and hVECshVSMCs media. Figure 3 A-C shows examples and figure 3 D summarizes the results. 
As seen in this figure, none of the three different conditioned media affected the distribution and levels of cytosolic and nuclear calcium in hVECs.

\section{Effect of conditioned medium of hVECs, hVSMCs and hVECs-hVSMCs co-culture on cytosolic and nuclear calcium of hVSMCs.}

In this series of experiments, we collected the 3 different conditioned culture media and we then exposed hVSMCs loaded with fluo-3 to each conditioned medium. Figure 4 A-C shows examples and figure $4 \mathrm{D}$ summarizes the results. Figure 4 shows that none of the three conditioned media affected the distribution and levels of cytosolic and nuclear calcium of hVSMCs. 


\section{Discussion and conclusions}

Our results showed that physical contacts between hVECs or hVSMCs do not affect distribution and levels of cytosolic and nuclear calcium in either type of vascular cells. These results confirm that physical contact between hVECs or hVSMCs does not induce any changes in these respective cells. Thus, we suggest that, whatever is the type of physical contact between hVECs or hVSMCs, it would not affect intracellular calcium homeostasis. The lack of effect of physical contact between the same type of cells could be due to the absence of electrical and chemical gradients between cells that have similar cytoplasmic chemical factors and resting potential. Our results also demonstrate that cultured hVECs or hVSMCs share the same distribution and levels of cytosolic and nuclear calcium. This confirms the purity and homogeneity of each type of cell used in this study.

Our results, however, showed for the first time that contrary to physical contact between the same cell type, physical contact between hVSMCs and hVECs triggers a significant increase of nuclear calcium level of hVECs without affecting intracellular calcium homeostasis of hVSMCs. Since the content of the cytoplasm of hVSMCs and hVECs is different, we postulate that an intracellular factor present only in hVSMCs or its concentration is higher in hVSMCs may have crossed the junction between the two cell types reaching the cytosol of hVECs. The presence of an hVSMCs factor in the cytosol of hVECs would bind to nuclear membranes' receptors (Bkaily et al., 2000, 2011) and directly modulate nuclear calcium. Such a factor, as demonstrated by other previous work in isolated nuclei, could be ET-1, neuropeptide Y (NPY) or angiotensin II (Ang II) (Bkaily et al., 2000, 2011). These factors however are usually synthesized at a higher rate 
by hVECs compared to hVSMCs. Thus, in the latter case we expect that these hVECs factors would also cross the hVECs-hVSMCs junctions (probably gap junctions) towards hVSMCs and affect nuclear calcium as was reported previously by our laboratory (Bkaily et al., 2000, 2011). Thus, we cannot exclude that the factor affecting hVECs nuclear calcium could be a hVSMCs-specific factor only present in this type of cells. Alternatively, the cytosolic level of the latter factor is higher in hVSMCs than in hVECs thus permitting its crossing through the gap junctions due to its driving force. This factor should be identified and studied in the future.

We cannot exclude, on the other hand, the possibility that such a hVSMC factor can be none other than ET-1, Ang II or NPY. This can be supported, to some extent, by literature in the field, including our work (Bkaily et al., 2011), that showed that intracellular injection of Ang II into VSMCs induced an increase of intracellular calcium (Zhuo et al., 2006; Haller et al., 1996) that was transmitted to the nucleus (Haller et al., 1996). The increase of intracellular calcium by intracellular microinjection of Ang II was due to the activation of $\mathrm{AT}_{1}$ receptors present intracellularly and this cellular response was only blocked by an intracellular $\mathrm{AT}_{1}$ receptor antagonist (Zhuo et al., 2006; Haller et al., 1996). In addition, in contrast to our finding, the increase of calcium level was mainly cytosolic and was attributed to intracellular calcium release from the endoplasmic reticulum (Zhuo et al., 2006) or influx of extracellular calcium (Haller et al., 1996). These differences between our findings and those reported using microinjection of Ang II (Zhuo et al., 2006; Haller et al., 1996) may be due to species differences (human vs. animal). Thus, it is important to verify in the future whether microinjection of antagonists 
of ET-1, Ang II or NPY receptors would prevent the modulation of nuclear calcium in hVECs induced by physical contact with hVSMCs.

Finally, our results show that the effect of physical contact between hVECs and hVSMCs is not due to a factor released by either cell type. This again supports our hypothesis that the increase of nuclear calcium in hVECs is due to a factor transmitted from hVSMCs to hVECs via newly formed gap junctions and/or a factor released from intracellular stores of hVSMCs or hVECs due to physical interaction. Such a factor can be due to electrical coupling between two types of cells that have different resting potentials such as hVSMCs (resting potential near $-60 \mathrm{mV}$ ) (Bkaily et al., 1994) and hVECs (resting potential near $-30 \mathrm{mV}$ ) (Voets et al., 1996). This would induce changes in the resting potential of hVECs and thus affects voltage gated channels present at the nuclear membranes, inclusive of the R-type calcium channels (Bkaily et al., 2011, 2015). Such an increase of nuclear calcium by a cytosolic hVSMCs factor would affect nuclear functions via stimulating several calcium-dependent transcription factors that are implicated in gene expression. Thus, an increase of physical contact between hVSMCs and hVECs could promote vascular diseases such as in hypertension, increase of vascular permeability and development of atherosclerosis. 


\section{Aknowledgements}

This work was supported by a CIHR grant to Dr. G. Bkaily (grant no. MOP-125932). 


\section{References}

Ahmarani, L., Avedanian, L., Al-Khoury, J., Perreault, C., Jacques, D., and Bkaily, G. 2013. Whole-cell and nuclear NADPH oxidases levels and distribution in human endocardial endothelial, vascular smooth muscle, and vascular endothelial cells. Can. J. Physiol. Pharmacol. 91(1):71-79.

Alberts, B. 1994. Cell functions, cell adhesion, and the extracellular matrix. In: Molecular biology of the cell. Third edition. Edited by D. Bray, J. Lewis, M. Raff, K. Roberts and J.D. Watson. Watson. Garland. pp: 950-999.

Avedanian, L., Riopel, J., Bkaily, G., Nader, M., D'Orleans-Juste, P., and Jacques, D. 2010. ETA receptors are present in human aortic vascular endothelial cells and modulate intracellular calcium. Can. J. Physiol. Pharmacol. 88(8):817-829.

Bény, JL. and Pacicca, C. 1994. Bidirectional electrical communication between smooth muscle and endothelial cells in the pig coronary artery. Am. J. Physiol. 266: H1465H1472.

Bkaily, G. and Jacques, D. 2010. Use of confocal Microscopy to investigate cell structure and function. In Techniques in confocal microscopy. Edited by P.M. Conn. Academic Press, Elsevier, Boston, USA. pp. 105-122.

Bkaily, G., Jacques, D., Hassan, G., Choufani, S., and D’Orleans-Juste, P. 2001. Using confocal imaging to measure changes in intracellular ions. In Receptors: structure and functions. Edited by C. Stanford and R. Horton. Oxford University Press, New York. pp. 209-231.

Bkaily, G., Sleiman, S., Stephan, J., Asselin, C., Choufani, S., Kamal, M., et al. 2003. Angiotensin II $\mathrm{AT}_{1}$ receptor internalization, translocation and de novo synthesis modulate 
cytosolic and nuclear calcium in human vascular smooth muscle cells. Can. J. Physiol. Pharmacol. 81: 274-287.

Bkaily, G., Al-Khoury, J., Simon, Y., and Jacques, D. 2017. Intracellular Free Calcium Measurement Using Confocal Imaging. Methods Mol. Biol. 1527:177-187.

Bkaily, G., Avedanian, L., Al-Khoury, J., Ahmarani, L., Perreault, C., and Jacques, D. 2012. Receptors and ionic transporters in nuclear membranes: new targets for therapeutical pharmacological interventions. Can. J. Physiol. Pharmacol. 90:953-965.

Bkaily, G., Avedanian, L., Al-Khoury, J., Provost, C., Nader, M., D'Orléans-Juste, P., and Jacques, D. 2011. Nuclear membrane receptors for ET-1 in cardiovascular function. Am. J. Physiol. Regul. Integr. Comp. Physiol. 300: R251-R263.

Bkaily, G., Avedanian, L., Al-Khoury, J., Chamoun, M., Semaan, R., Jubinville-Leblanc, C., D'Orléans-Juste, P., and Jacques, D. 2015. Nuclear membrane R-type calcium channels mediate cytosolic ET-1-induced increase of nuclear calcium in human vascular smooth muscle cells. Can. J. Physiol. Pharmacol. 93(4):291-297.

Bkaily, G., Jacques, D., and Pothier, P. 1999. Use of confocal microscopy to investigate cell structure and function. Methods Enzymol. 307:119-135.

Bkaily, G., Choufani, S., Hassan, G., El-Bizri, N., Jacques, D., and D'Orléans-Juste, P. 2000. Presence of functional endothelin-1 receptors in nuclear membranes of human aortic vascular smooth muscle cells. J. Cardiovasc. Pharmacol. 36:S414-S417.

Bkaily, G., P. Pothier, P. D’Orléans-Juste, M. Simaan, D. Jacques, D. Jaalouk, F. Belzile, C. Boutin, G. Haddad, and W. Neugebauer. 1997. The use of confocal microscopy in the investigation of cell structure and function in heart, vascular endothelium and smooth muscle cells. Mol. Cell. Biochem. 172:171-194. 
Bkaily, G. 1994. General Electrophysiology of vascular smooth muscle (VSM). In: Ionic Channels in Vascular Smooth Muscle. G Bkaily (ed). Mol. Biol. Intelligence Unit, Austin, 1994, pp 1-8.

Christ, G.J., Spray, D.C., El-Sabban, M., Moore, L.K., and Brink, P.R. 1996. Gap junctions in vascular tissues: evaluating the role of intercellular communication in the modulation of vasomotor tone. Circ. Res. 79:631-646.

Cuevas, P., and Gutierrez Diaz, J.A. 1982. Smooth muscle cells in 'venous patches' grafted into the rat common carotid artery. A structural study. Experientia. 38:122-124.

Cuevas, P., Gutierrez Diaz, J.A., and Reimers, D. 1982. Intercellular junctions between smooth muscle cells in myointimal hyperplasia. Acta Anat. 114: 22-32.

DeLisser, H.M., Newman P. J., and Albelda, S.M. 1994. Molecular and functional aspects of PECAM-1/CD31. Immunol. Today. 15: 490-495.

Donahue H.J., Qu R.W., and Genetos D.C. 2017. Joint diseases: from connexins to gap junctions. Nat. Rev. Rheumatol. 14: 42-51.

Elfgang C., Eckert, R., H. Lichtenberg-Fraté, A., Butterweck, O., Traub, R.A. Klein, D.F. Hülser, K., and Willecke. 1995. Specific permeability and selective formation of gap junction channels in connexin-transfected HeLa cells. J. Cell. Biol.129: 805-817.

Goodenough, D.A. 1979. Gap junction dynamics and intercellular communication. Pharmacol. Rev. 30: 383-392.

Grünwald, J., Robenek, H., Mey, J., and Hauss, W. H. 1982. In vivo and in vitro cellular changes in experimental hypertension: electron microscopic and morphometric studies of aortic smooth muscle cells. Exp. Mol. Pathol. 36: 164-176. 
Haller, H., Lindschau, C., Erdmann, B., Quass, P., and Luft, F.C. 1996. Effects of intracellular angiotensin II in vascular smooth muscle cells. Circ. Res. 79(4):765-772. Hirshi, K.K., S.A. Rohovsky, L.H. Beck, Smith, S.R. and D'Amore, P.A. 1999. Endothelial cells modulate the proliferation of mural cell precursors via platelet-derived growth factor-BB and heterotypic cell contact. Circ. Res. 84: 298-305.

Hüttner, I., Walker, C., and Gabbiani, G. 1985. Aortic endothelial cell during regeneration: remodeling of cell junctions, stress fibers, and stress fiber-membrane attachement domains. Lab. Invest. 53: 287-302.

Hynes, R.O. 1987. Integrins : a family of cell surface receptors. Cell. 48: 549-554.

Spagnoli, L.G., Villaschi, S., Neri, L., and Palmieri, G. 1982. Gap junctions in myoendothelial bridges of rabbit carotid arteries. ExperIentia. 38: 124-125.

Kurtz, A. 2015. Connexins, renin cell displacement and hypertension. Curr. Opin .Pharmacol. 21:1-6.

Meda, P. 2018. Gap junction proteins are key drivers of endocrine function. Biochim. Biophys. Acta. 1860:124-140.

Okamoto, T., and Suzuki, K. 2017. The Role of Gap Junction-Mediated Endothelial CellCell Interaction in the Crosstalk between Inflammation and Blood Coagulation. Int. J. Mol. Sci. 18. pii: E2254.

Voets, T., Droogmans, G., and Nilius, B. 1996. Membrane currents and the resting membrane potential in cultured bovine pulmonary artery endothelial cells. J. Physiol. 497:95-107. 
Zhuo, J.L., Li, X.C., Garvin, J.L., Navar, L.G., and Carretero, O.A. 2006. Intracellular ANG II induces cytosolic Ca2+ mobilization by stimulating intracellular AT1 receptors in proximal tubule cells. Am. J. Physiol. Renal Physiol. 290(6):F1382-1390. 


\section{Figure legends}

Figure 1: Modulation of $[\mathrm{Ca}]_{\mathrm{c}}$ and $[\mathrm{Ca}]_{\mathrm{n}}$ of hVECs by physical contact with hVSMCs.

Quantitative 3D confocal microscopy images showing the distribution of cytosolic and nuclear $\mathrm{Ca}^{2+}$ in hVECs in pure culture of hVECs without contact (A) and in contact with other hVECs (B) as well as in co-culture with hVSMCs (C). In the inserts of panel C, we increased the fluorescence intensity gain in order to clearly show the contacts between hVECs and hVSMCs. The intensity value in these inserts has no measurable meaning. The bar diagram (D) shows the quantification and statistical analysis of the results shown in $\mathrm{A}, \mathrm{B}$ and $\mathrm{C}$. The values are presented as means \pm S.E.M. The number of experiments varies from 36 to 117 from at least 3 different experiments. The pseudocolor scale represents the level of fluorescence intensity of the Fluo-3-Ca ${ }^{2+}$ complex from 0 (Black, absence of fluorescence) to 255 (White, max fluorescence) in panels A, B and C. The white scale bar is in $\mu \mathrm{m}$.

Figure 2: Modulation of $[\mathrm{Ca}]_{\mathrm{c}}$ and $[\mathrm{Ca}]_{n}$ of $\mathrm{hVSMCs}$ by physical contact with hVECs.

Quantitative 3D confocal microscopy images showing the distribution of cytosolic and nuclear $\mathrm{Ca}^{2+}$ in hVSMCs in pure culture of hVSMCs without contact (A) and in contact with other hVSMCs (B) as well as in co-culture with hVECs (C). The bar diagram (D) shows the quantification and statistical analysis of the results shown in A, B and C. The values are presented as means \pm S.E.M. The number of experiments varies from 19 to 34 from at least 3 different experiments. The pseudocolor scale represents the level of fluorescence intensity of the Fluo-3- $\mathrm{Ca}^{2+}$ complex from 0 (Black, absence of 
fluorescence) to 255 (White, max fluorescence) in panels A, B and C. The white scale bar is in $\mu \mathrm{m}$.

Figure 3: Absence of effect of long-term conditioned media on the basal level of $[\mathbf{C a}]_{\mathbf{c}}$ and $[\mathbf{C a}]_{\mathbf{n}}$ in hVECs. Panel $\mathrm{A}, \mathrm{hVECs}$ exposed to a medium conditioned by hVECs. Panel B, hVECs in the presence of medium conditioned by hVSMCs. Panel C, hVECs exposed to medium conditioned by co-culture of hVECs-hVSMCs. The bar diagram (D) shows the quantification and statistical analysis of the results shown in A, B and C. The values are presented as means \pm S.E.M. The number of experiments varies from 18 to 52 from at least 3 different experiments. The pseudocolor scale represents the level of fluorescence intensity of the Fluo-3-Ca ${ }^{2+}$ complex from 0 (Black, absence of fluorescence) to 255 (White, max fluorescence) in panels A, B and C. The white scale bar is in $\mu \mathrm{m}$.

Figure 4: Absence of effect of long-term conditioned media on the basal level of $[\mathbf{C a}]_{\mathbf{c}}$ and $[\mathbf{C a}]_{\mathbf{n}}$ in hVSMCs. Panel A, hVSMCs exposed to a medium conditioned by hVSMCs. Panel B, hVSMCs in the presence of medium conditioned by hVECs. Panel C, hVSMCs exposed to medium conditioned by co-culture of hVECs-hVSMCs. The bar diagram (D) shows the quantification and statistical analysis of the results shown in A, B and C. The values are presented as means \pm S.E.M. The number of experiments varies from 19 to 52 from at least 3 different experiments. The pseudocolor scale represents the level of fluorescence intensity of the Fluo-3-Ca ${ }^{2+}$ complex from 0 (Black, absence of fluorescence) to 255 (White, max fluorescence) in panels A, B and C. The white scale bar is in $\mu \mathrm{m}$. 

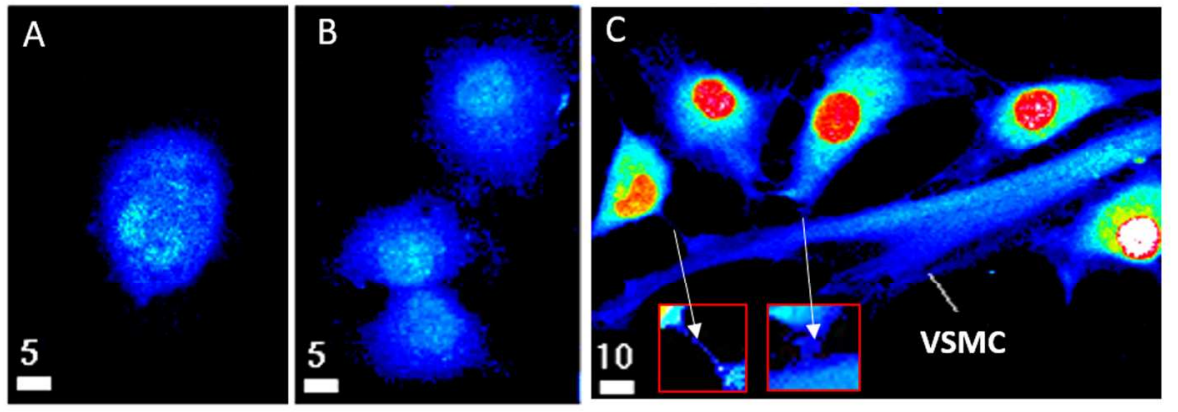

D

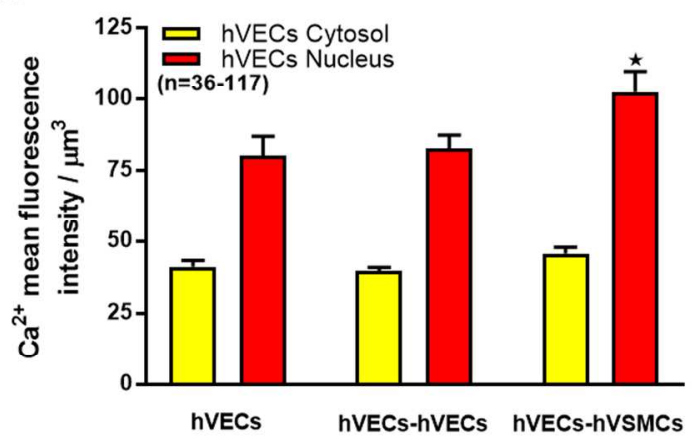

Figure 1: Modulation of [Ca]c and [Ca]n of hVECs by physical contact with hVSMCs.

Quantitative 3D confocal microscopy images showing the distribution of cytosolic and nuclear Ca2+ in hVECs in pure culture of hVECs without contact (A) and in contact with other hVECs (B) as well as in co-culture with hVSMCs (C). In the inserts of panel C, we increased the fluorescence intensity gain in order to clearly show the contacts between hVECs and hVSMCs. The intensity value in these inserts has no measurable meaning. The bar diagram (D) shows the quantification and statistical analysis of the results shown in $A, B$ and C. The values are presented as means \pm S.E.M. The number of experiments varies from 36 to 117 from at least 3 different experiments. The pseudocolor scale represents the level of fluorescence intensity of the Fluo-3-Ca2+ complex from 0 (Black, absence of fluorescence) to 255 (White, max fluorescence) in panels A, $B$ and $C$. The white scale bar is in $\mu \mathrm{m}$.

$184 \times 152 \mathrm{~mm}(300 \times 300$ DPI $)$ 

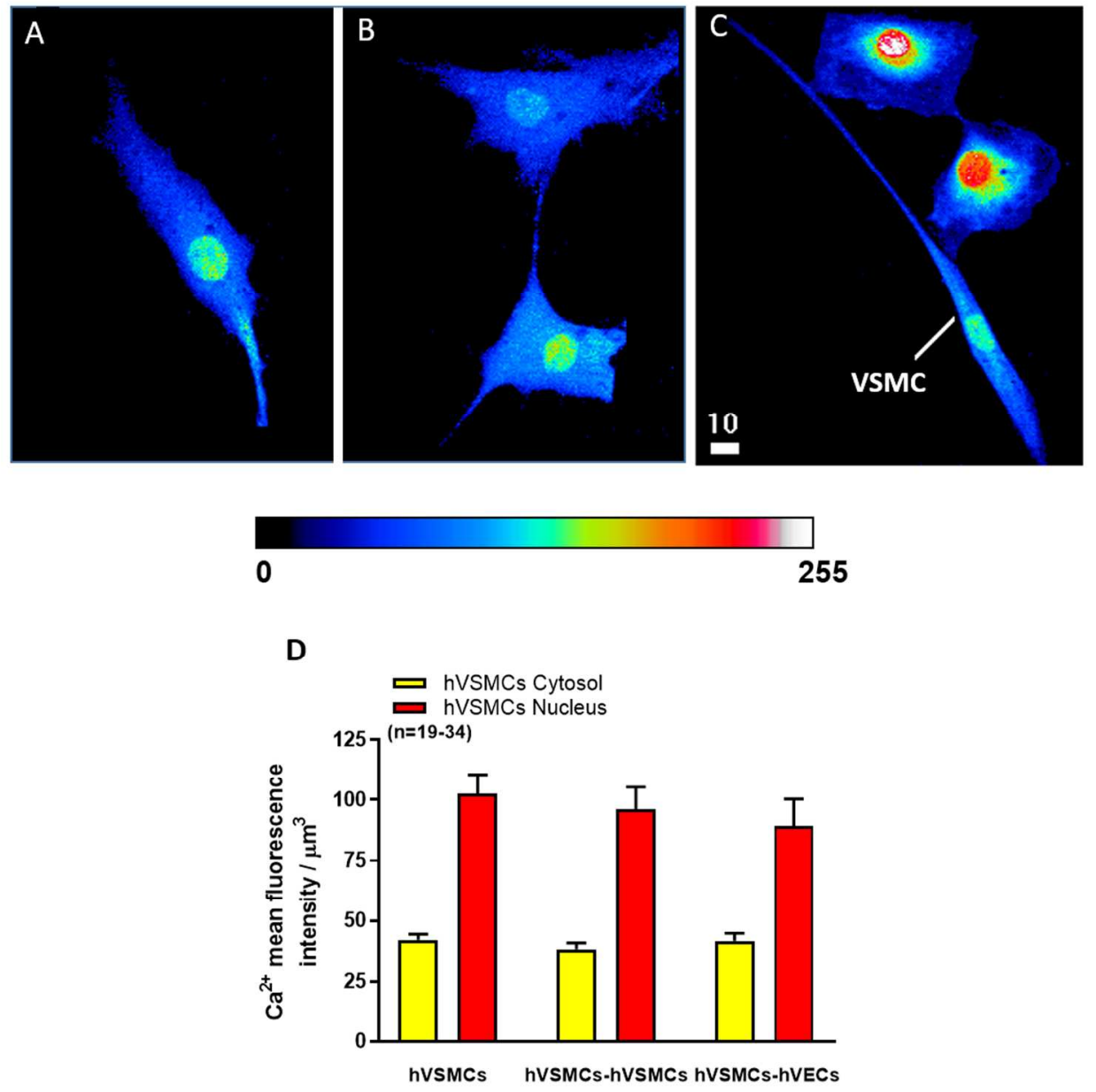

Figure 2: Modulation of [Ca]c and [Ca]n of hVSMCs by physical contact with hVECs.

Quantitative 3D confocal microscopy images showing the distribution of cytosolic and nuclear $\mathrm{Ca} 2+$ in hVSMCs in pure culture of hVSMCs without contact (A) and in contact with other hVSMCs (B) as well as in co-culture with hVECs (C). The bar diagram (D) shows the quantification and statistical analysis of the results shown in $A, B$ and $C$. The values are presented as means \pm S.E.M. The number of experiments varies from 19 to 34 from at least 3 different experiments. The pseudocolor scale represents the level of fluorescence intensity of the Fluo-3-Ca2+ complex from 0 (Black, absence of fluorescence) to 255 (White, max fluorescence) in panels $A, B$ and $C$. The white scale bar is in $\mu \mathrm{m}$. 

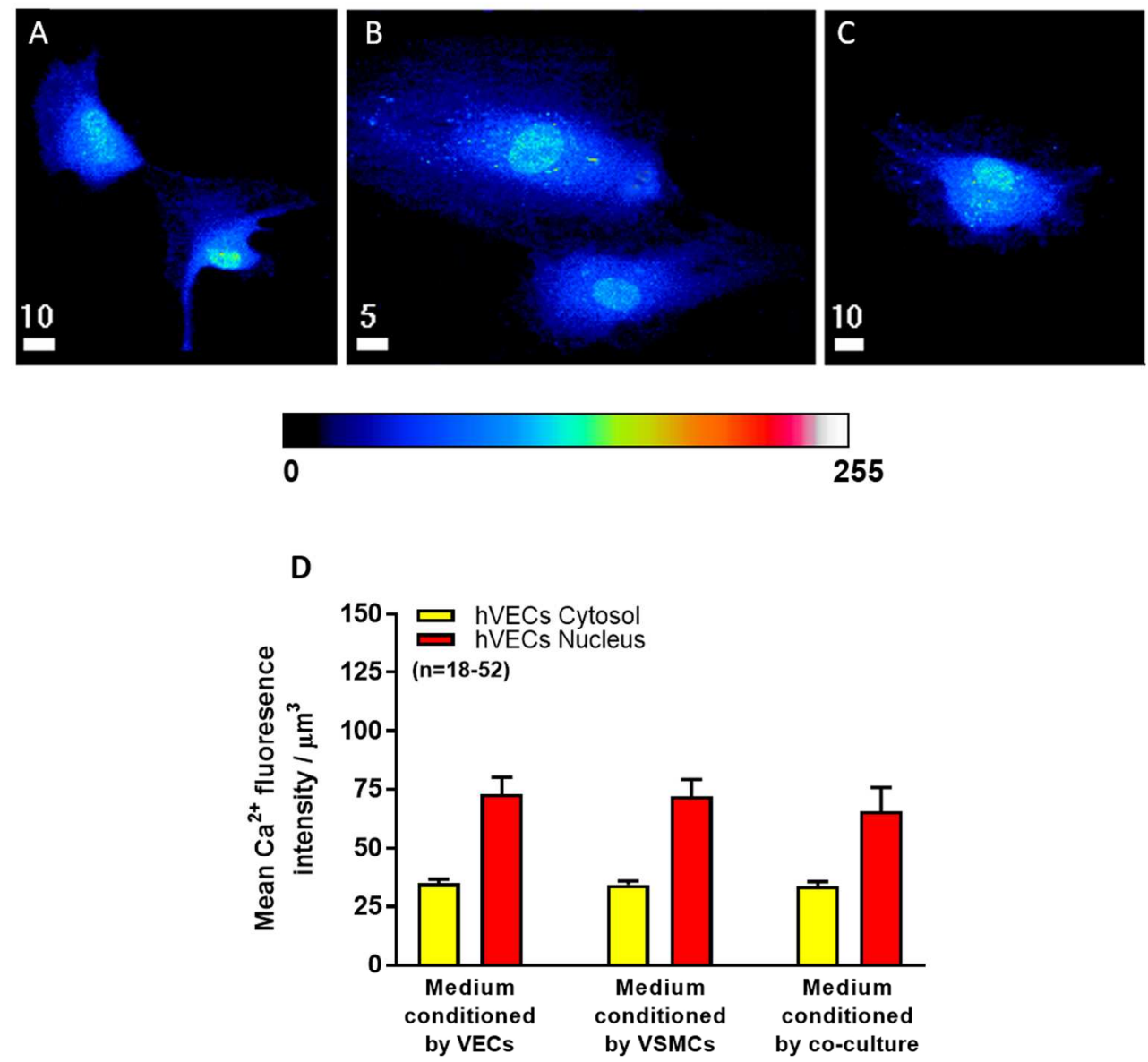

Figure 3: Absence of effect of long-term conditioned media on the basal level of [Ca]c and [Ca]n in hVECs. Panel A, hVECs exposed to a medium conditioned by hVECs. Panel B, hVECs in the presence of medium conditioned by hVSMCs. Panel C, hVECs exposed to medium conditioned by co-culture of hVECs-hVSMCs. The bar diagram (D) shows the quantification and statistical analysis of the results shown in A, B and C. The values are presented as means \pm S.E.M. The number of experiments varies from 18 to 52 from at least 3 different experiments. The pseudocolor scale represents the level of fluorescence intensity of the Fluo-3$\mathrm{Ca} 2+$ complex from 0 (Black, absence of fluorescence) to 255 (White, max fluorescence) in panels A, B and C. The white scale bar is in $\mu \mathrm{m}$. 

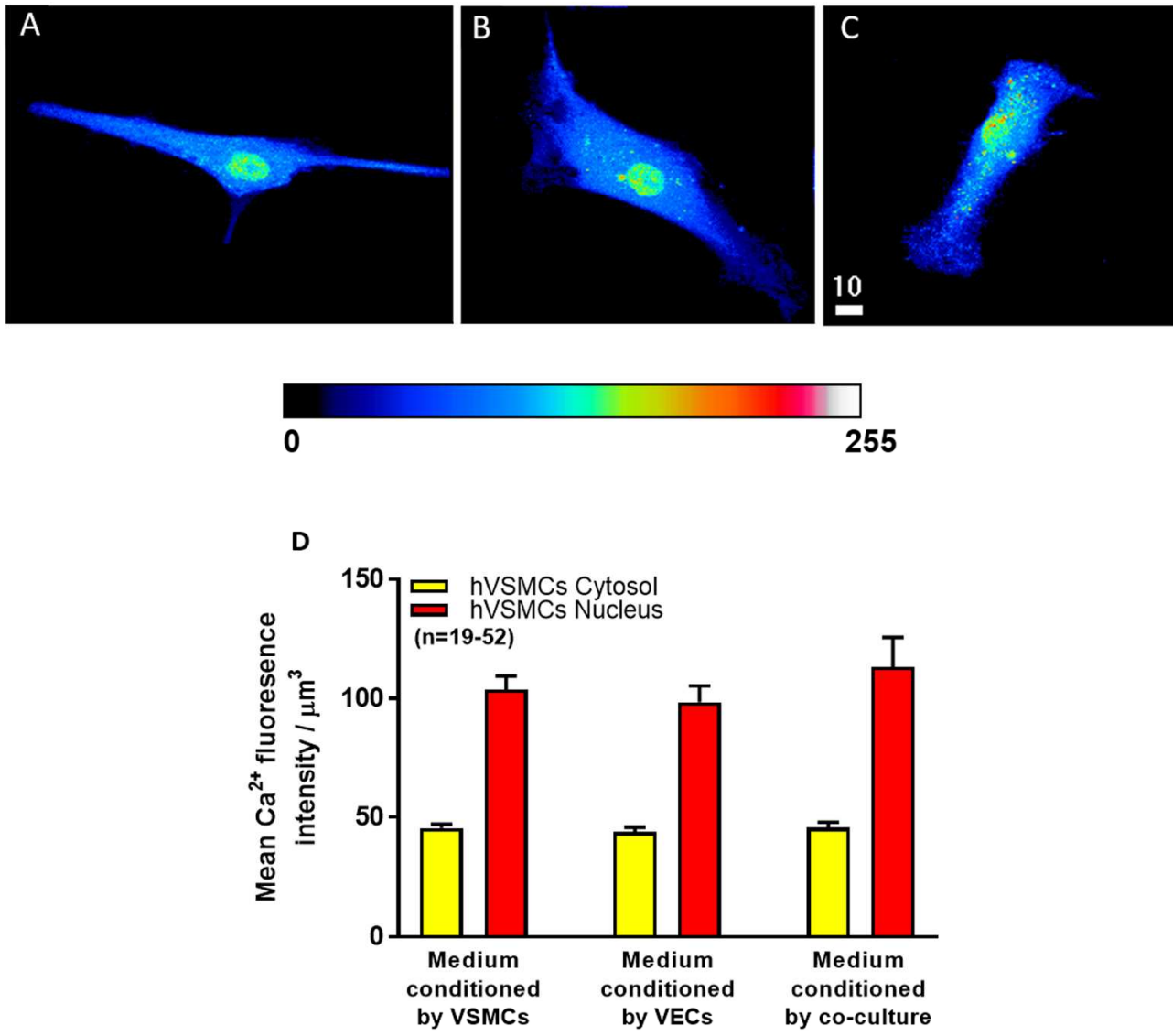

Figure 4: Absence of effect of long-term conditioned media on the basal level of [Ca]c and [Ca]n in hVSMCs. Panel A, hVSMCs exposed to a medium conditioned by hVSMCs. Panel B, hVSMCs in the presence of medium conditioned by hVECs. Panel C, hVSMCs exposed to medium conditioned by co-culture of hVECs-hVSMCs. The bar diagram (D) shows the quantification and statistical analysis of the results shown in A, B and C. The values are presented as means \pm S.E.M. The number of experiments varies from 19 to 52 from at least 3 different experiments. The pseudocolor scale represents the level of fluorescence intensity of the Fluo-3$\mathrm{Ca} 2+$ complex from 0 (Black, absence of fluorescence) to 255 (White, max fluorescence) in panels A, B and C. The white scale bar is in $\mu \mathrm{m}$.

$186 \times 180 \mathrm{~mm}(300 \times 300$ DPI $)$ 